\title{
CONVERSÃO E CONSUMO RELIGIOSO NAS NOVAS RELIGIÕES JAPONESAS: A IGREJA MESSIÂNICA E A PERFECT LIBERTY
}

Andréa Gomes Santiago Tomita

RESUMO: A partir da segunda metade do século XX, o cenário religioso brasileiro passa pelo fenômeno do surgimento das Novas Religiões Japonesas, principalmente, nos grandes centros urbanos e em regiões rurais com grande concentração de imigrantes japoneses. Ultrapassando os limites impostos pelas diferenças culturais e lingüísticas, gradativamente, as Novas Religiões Japonesas ganham seu espaço entre os brasileiros, inclusive das grandes cidades. Este artigo aborda alguns aspectos de duas Novas Religiões Japonesas no Brasil: a Igreja Messiânica Mundial (IMM) e a Perfect Liberty (PL), levantando questões sobre conversão e consumo religioso, freqüentemente analisadas pela Sociologia da Religião. A primeira parte consta de comentários sobre as novas religiões no Japão, algumas de suas características e o surgimento da Igreja Messiânica e a Perfect Liberty no Brasil. Posteriormente, apresentamos um visão geral das atividades específicas das duas religiões, procurando relacioná-las aos temas conversão e consumo religioso.

ABSTRACT: From the second half of 20th century on, Brazilian religious scenery has undergone a particular phenomenon: the expansion of New Japanese Religions (NJR). In the beginning, it took place, specially, among Japanese immigrants and their descendents in rural areas. By overcoming the hindrances caused by the cultural and linguistic differences, the NJR has gradually spread among the Brazilian population in urban areas. This article provides an account of some aspects of two NJR - Sekai Kyusei Kyô (which is known in Brazil as "Igreja Messiânica") and Perfect Liberty and discusses relevant themes to Sociology of Religion. The first part brings some issues about NJR in general in Japan, their characteristics and the appearance of Sekai Kyusei Kyo and Perfect Liberty in Brazil. The later one focuses on the activities of these religions relating them to conversion and religious consumption. 
PALAVRAS-CHAVE: Novas Religiões Japonesas, Igreja Messiânica, Perfect Liberty, conversão, consumo religioso.

KEYWORDS: New Japanese Religions, Sekai Kyusei Kyô (The Church of World Messianity), Perfect Liberty, conversion, religious consumption.

\section{Introdução}

A tendência de se generalizar as coisas, muitas vezes, é motivo de contratempos e confusões. Quanto mais desconhecido o assunto, maior a possibilidade de generalizações infundadas.

Novas Religiões Japonesas (shin-shûkyô) são facilmente confundidas entre si ou com o Budismo. O Johrei passa a ser uma prática da Seichô-no-ie e a Perfect Libertv que também cultua os antepassados pode ser confundida como uma ramificação do Budismo. Certamente, ninguém tem obrigação de saber diferenciar atividades e características de "religiões estrangeiras" com pouca visibilidade no cenário religioso brasileiro e repletas de facetas culturais tão particulares.

Esse argumento tipicamente nacionalista poderia até convencer em outros tempos. Entretanto, é fato que a partir da segunda metade do século XX, várias religiões japonesas começaram a surgir no Brasil, principalmente, nos grandes centros urbanos e em regiões rurais com grande concentração de imigrantes japoneses.

Com o decorrer dos anos, algumas das novas religiões japonesas aumentaram o número de fiéis no Brasil e, inclusive ultrapassando os limites impostos pela cultura e comunicação, expandiram seu rebanho por todo o mundo.

Neste trabalho pretendemos apresentar alguns aspectos de duas novas religiões japonesas no Brasil enfocando questões sobre conversão e consumo religioso, freqüentemente analisadas em disciplinas como Sociologia da Religião ou Psicologia da Religião. Abordaremos, especificamente, a Igreja Messiânica Mundial'2 (IMM) e a Perfect Liberty (PL) dividindo a análise em duas partes.

A primeira parte consta de comentários sobre as novas religiões no Japão, algumas de suas características e o surgimento da Igreja Messiânica e a Perfect Liberty no Brasil. Cremos que a visão geral do surgimento das novas religiões japonesas nos respectivos países, com história e cultura amplamente diferentes, trará informações úteis à compreensão da segunda parte: conversão e consumo religioso relacionados às duas religiões aqui estudadas.

1. Rito praticado pelos membros da Igreja Messiânica onde se faz a transmissão de energia cósmica para a purificação do espírito e da matéria.

2. Tendo em vista a existência de textos da bibliografia onde o nome "Igreja Messiânica" não aparece. esclarecemos que, em português, Sekai Kyusei Kyô significa Igreja Messiânica.

8 TOMITA, Andréa Gomes Santigo. Conversão e Consumo Religioso nas Nov'as Religiões Japonesas:... 


\section{Novas Religiões no Japão}

O Japão, apesar de sua pequena extensão, possui tantas religiões que, geralmente, é chamado de "museu das religiões" Conforme o Anuário das Religiões - 1999, o número total de fiéis de todas as instituições religiosas do Japão é de 207.760.000 pessoas, enquanto a população do país é de apenas 126.170.000. Observa-se que o número de fiéis ultrapassa 1,6 vezes o contingente populacional (Imidas, 1999). Diante desta realidade, considerar o japonês um povo extremamente religioso seria até normal.

É neste momento que a freqüência ao templo ou a participação em atividades religiosas são questionadas como formas de avaliação do grau de religiosidade de um povo: "Os japoneses freqüentam os templos budistas como os cristãos vão à missa aos domingos?" ou "Os japoneses guardam algum dia especial da semana como fazem os judeus?"

Hirochika Nakamaki responde com humor: "os japoneses transformaram o domingo num dia de descanso; dia para dormir e tirar o cansaço excessivo de uma semana de trabalho" Embora, atualmente, devido à ocidentalização, haja atividades religiosas nos fins de semana, o normal é seguir os dias de festividades dos templos xintoístas (en-nichi) conforme a tradição do antigo calendário lunar ou realizar festividades mensais (tsuki-nami-sai). "Como o Japão se modernizaria se gastasse tanto tempo em reuniões semanais ou nas 5 reverências diárias feitas pelos mulçumanos?" Concluindo, o autor diz que "o japonês é um religioso moderado" (Nakamaki, 1990, pp. 150-151)

No Japão, as religiões xintoísta e budista estão intimamente ligadas entre si e também muito presentes no cotidiano do povo japonês não somente pelo aspecto religioso, mas também pelo cultural. Segundo estatísticas (Imidas, 1999), 102.213.787 japoneses ( $81 \%$ da população) são fiéis xintoístas, ou seja, praticamente a população inteira. Ao mesmo tempo, 91.583 .843 japoneses ( $72 \%$ da população) crêem em religiões de origem budista. Porém, quando enfocamos os fiéis ativos do xintoísmo ou do budismo, observamos que a realidade difere dos números das pesquisas. Isto porque os templos xintoístas e budistas contam como fiéis todos aqueles que são registrados nas áreas dos seus respectivos templos. Assim, não é difícil alcançar números tão altos. É evidente, portanto, que o mesmo fiel atende aos anseios de sua alma ora numa ora noutra religião.

E sobre a realidade das novas religiões japonesas ${ }^{3}$ (NRJ)? Com tantos budistas e xintoístas haveria espaço para a propagação de novas religiões no Japão como a IMM e a PL?

Segundo o prefácio do Dicionário de Novas Religiões, "no Japão da atualidade, mais de $10 \%$ da população, de alguma forma, está ligada a uma NRJ. Mais do que se possa imaginar, isso representa uma forte repercussão na política, economia e cultura entre outros aspectos. Além de atividades e conteúdos relativamente comuns entre si, tais como a prática da cura de doenças e o sufrágio aos antepassados, as atividades das NRJ abrangem diversas áreas: educacional, médica, assistência social, voluntariado

3. A partir daqui, passaremos a usar a sigla NRJ para referir-nos às Novas Religiões Japonesas. 
etc. Ao mesmo tempo, é crescente o número de organizações religiosas que estão se empenhando na sua expansão no exterior do país." (Inoue, 1996, p. iii)

No trecho acima o autor não diz que "mais de $10 \%$ da população, de alguma forma, se converteu a uma NRJ" Diferentemente do brasileiro, na grande maioria católico de crença monoteísta; o japonês, desde os primórdios, aceita a pluralidade de deuses. Neste sentido, seria possível lançar a hipótese de que a questão do drama da conversão (Prandi, 2000) pode assumir conotações diversas conforme o contexto religioso-cultural, Por exemplo, em japonês, a palavra "conversão" é mais usada no caso de conversão ao cristianismo cujo sistema doutrinário e simbólico difere completamente do das religiões tradicionais nascidas no Oriente. Converter-se ou ligar-se a uma NRJ - caracterizada pelo sincretismo e pela diversificação de serviços oferecidos representa uma ruptura muito mais social do que religiosa-cultural. Dentre outros aspectos, a forte repulsa e o preconceito da sociedade japonesa com relação às NRJ reforçaria a ruptura social daquele que "ousa" filiar-se a uma NRJ.

\section{Algumas Características das Novas Religiões Japonesas}

Dentre as várias características das NRJ, podemos citar a presença de um Fundador que transmite Ensinamentos revelados por alguma divindade. Em maior ou menor grau, a maioria é de caráter sincrético, tendo incorporado livremente ensinamentos e práticas de várias outras religiões ou filosofias (Budismo, Xintoísmo, Cristianismo, Confucionismo etc.). Em geral, sua doutrina e ritual tendem a ser simples e descomplicados. Apresentam forte influência de religiões populares como o xamanismo e, por isso, muitas delas realizam práticas religiosas visando a cura de doenças (Matsue, 2002).

Crêem na realização do paraíso na terra, apresentando, portanto, traços milenaristas. A este respeito, Peter B.Clarke, classifica a Igreja Messiânica como um movimento milenarista em expansão no Brasil. "Na história da Igreja Messiânica pode-se detectar uma transição, de uma resposta radicalmente milenarista do mundo [...] para uma resposta que se pode caracterizar como mais gradual e reformista. [...] o compromisso com a construção do paraíso na Terra [...] permanece como meta prioritária do movimento." (Clarke, 2000,p. 107)

$\mathrm{O}$ culto aos antepassados também é uma característica comum à maioria das NRJ. Tanto a IMM como a PL incluem-se neste caso, cada qual com ritos e argumentos próprios. Segundo Yumi Fujikura, "na PL, os adeptos aprendem a orar para os antepassados diretamente, pedindo a eles proteção para a família e perdão pelas faltas cometidas enquanto os mesmos tinham vida. Aprendem a respeitar seus antepassados, pois a eles devem não só sua vida, mas tudo que possuem de bom ou de mau." (Fujikura, 1992, p. 99)

\section{A Igreja Messiânica e a Perfect Liberty no Brasil}

As NRJ chegam ao Brasil por intermédio dos imigrantes japoneses e posteriormente através de missionários enviados especialmente para divulgá-las. Entretanto, não se pode dizer que os japoneses tinham vida religiosa verdadeiramente ativa no 
período inicial da imigração até a eclosão da II Guerra Mundial (Mori, 1988). Grosso modo, este período caracteriza-se pelo respeito e comedimento diante da igreja católica e do nacionalismo brasileiro.

De meados dos anos 30 à década de 50, mudanças importantes ocorreram na sociedade brasileira e também nas colônias japonesas com seus descendentes. A migração de grandes contingentes de japoneses para São Paulo e a participação na crescente classe média podem ser consideradas condições ideais para a expansão das $\mathrm{NRJ}^{4}$ no Brasil. A ascensão econômica e social, a urbanização do país e o surgimento do pensamento de permanência definitiva no Brasil, entre outros, constituem o pano de fundo social deste fenômeno.

A IMM e a PL são instituições religiosas de origem japonesa que representam uma nova modalidade de fervor religioso nas camadas médias urbanas brasileiras (Gonçalves, 1998). Ambas, inicialmente, expandiram-se entre os imigrantes, porém, atualmente, a grande maioria de seus adeptos são brasileiros natos sem qualquer ascendência japonesa ou oriental.

A Igreja Messiânica começou suas atividades no Brasil em 1955. Nos primeiros 15 anos seu crescimento foi pequeno e ela permaneceu uma religião pequena e étnica [...]. Então, pelos fins dos anos 60, começou a experimentar uma expansão fenomenal e se transformou numa religião multiétnica. À época em que escrevo, junho de 2000 , o número de membros é estimado em 350.000 (Clarke, 2000, p. 111).

A PL é uma instituição religiosa de origem japonesa que possui atualmente no Brasil cerca de 70.000 adeptos ativos e 216 locais de culto. Ao lado da Seichô-no-iê, Igreja Messiânica, Sôka Gakkai e Arte Mahikari, é uma das religiões japonesas com maior número de membros no país. [...] A PL foi fundada no Japão e começou a ser introduzida no Brasil em 1957 através da colônia japonesa. Não demorou muito para que a PL começasse a se expandir também entre os brasileiros, passando, em poucos anos, de religião restrita ao grupo étnico para religião de caráter universal. [...] Na sua estratégia de expansão, procura se adaptar à cultura do país aonde chega, através do uso intenso do idioma local, formação de clero nativo e incorporação de hábitos locais (Gonçalves, 1998, p. 3).

\section{Conversão e Consumo Religioso}

Consumo religioso, entretanto, não implica necessariamente conversão.

PRANDI, 1996

Inspirados num conceito originariamente pedagógico, arriscamo-nos a afirmar que a interdisciplinaridade peculiar às NRJ legitima a afirmativa acima. No caso das NRJ, certamente, conversão e consumo religioso são coisas distintas.

4. Chamo de "surgimento das NRJ" aquilo que Koichi Mori (Mori, 1988, p. 575) chamou de "ressureição das religiões de origem japonesa", visto que o autor trata não somente das NRJ, mas também de religiões tradicionais como o xintoísmo e budismo. 
Como já foi dito anteriormente, embora sejam instituições religiosas, as NRJ, na realidade, atuam em várias áreas que não só a religiosa ${ }^{5} \mathrm{Em}_{\text {geral, o cárater abrangente }}$ das doutrinas ou filosofias das NRJ permite uma grande variedade de serviços e produtos, além de possuir um público-alvo cujo interesse é bastante heterogêneo. A seguir, passamos a uma breve descrição de algumas atividades da IMM e da PL, no Brasil.

A Igreja Messiânica Mundial do Brasil (IMMB) ${ }^{6}$ possui até mesmo entidades coligadas. Em 1971, instituiu a Fundação Mokiti Okada (FMO) com o objetivo de desenvolver atividades ultra-religiosas ${ }^{7}$ que contribuam para o desenvolvimento global do ser humano e para a formação de um mundo melhor. Em 1994, estabeleceu a KORIN Agropecuária com o objetivo de produzir e comercializar produtos hortifrutigrangeiros, isentos de agrotóxicos e de promotores de crescimento, visando tornar mais sadia a alimentação humana.

Em 1995, a IMMB inaugurou o Solo Sagrado em Guarapiranga, São Paulo (Fotol, página seguinte). Trata-se de um vasto complexo que combina edificações e paisagens naturais e se destina não somente aos adeptos messiânicos, mas também a pessoas de diferentes credos. "A Sede (do Movimento Mokiti Okada) ${ }^{8}$ também abriga um centro cultural, alojamento para 300 pessoas, postos de saúde e praças de alimentação e já é considerada um ponto turístico na região, recebendo cerca de 50 mil pessoas por mês, independente de estarem ou não ligadas ao Movimento. O local é aberto para todos os que estiverem interessados em obter um pouco de paz e harmonia em meio ao caos da cidade de São Paulo." (Revista Johrei, 2000, p. 38)

Dentre as atividades da FMO destacam-se: na área artístico-cultural, a apreciação do belo através do Ikebana (estilo Sanguetsu), da Cerâmica e do Canto Coral; na área educacional, o Projeto Planeta Azul que busca encaminhar as crianças para o altruísmo e na área ecológica, a prática da Agricultura Natural objetivando a preservação do meio ambiente. Estes serviços ou produtos podem estar disponíveis tanto nos Johrei Center ${ }^{9}$ quanto em espaços considerados "neutros" como o Solo Sagrado onde existe uma tentativa de abordagem ultra-religiosa ${ }^{10} \mathrm{e}$ a grande maioria dos visitantes não é filiada à IMMB.

5. Pierucci trata da "diversificação de serviços oferecidos" (Pierucci, 1996).

6. Uma vez que no Brasil há dissidências da religião messiânica (Comunidade Messiânica Universal e Templo Luz do Oriente), é importante destacar que neste trabalho serão citadas apenas as atividades da Igreja Messiânica Mundial do Brasil (IMMB).

7. Mokiti Okada, fundador da Igreja Messiânica, escreve o artigo "Ultra-Religião" onde lança a idéia de uma religião de caráter abrangente que, além da religião, contenha outros aspectos da cultura como arte. ciência, filosofia etc.

8. Movimento baseado nos ideais de Mokiti Okada. Busca a união de conceitos de espiritualidade e teorias científicas, especialmente por meio de pesquisas científicas sobre o Johrei e a Agricultura Natural, além da realização de projetos na área artística, educacional etc. Caracteriza-se por atividades que transcendem o limite da religião e abrangem todas as demais expressões da cultura humana como Filosofia, Arte. Ciência etc. (Tomita, 2002).

9. Johrei Center é o nome dado às unidades religiosas da IMMB. Johrei é a principal atividade religiosa da IMM.

10. Vide nota 7. 


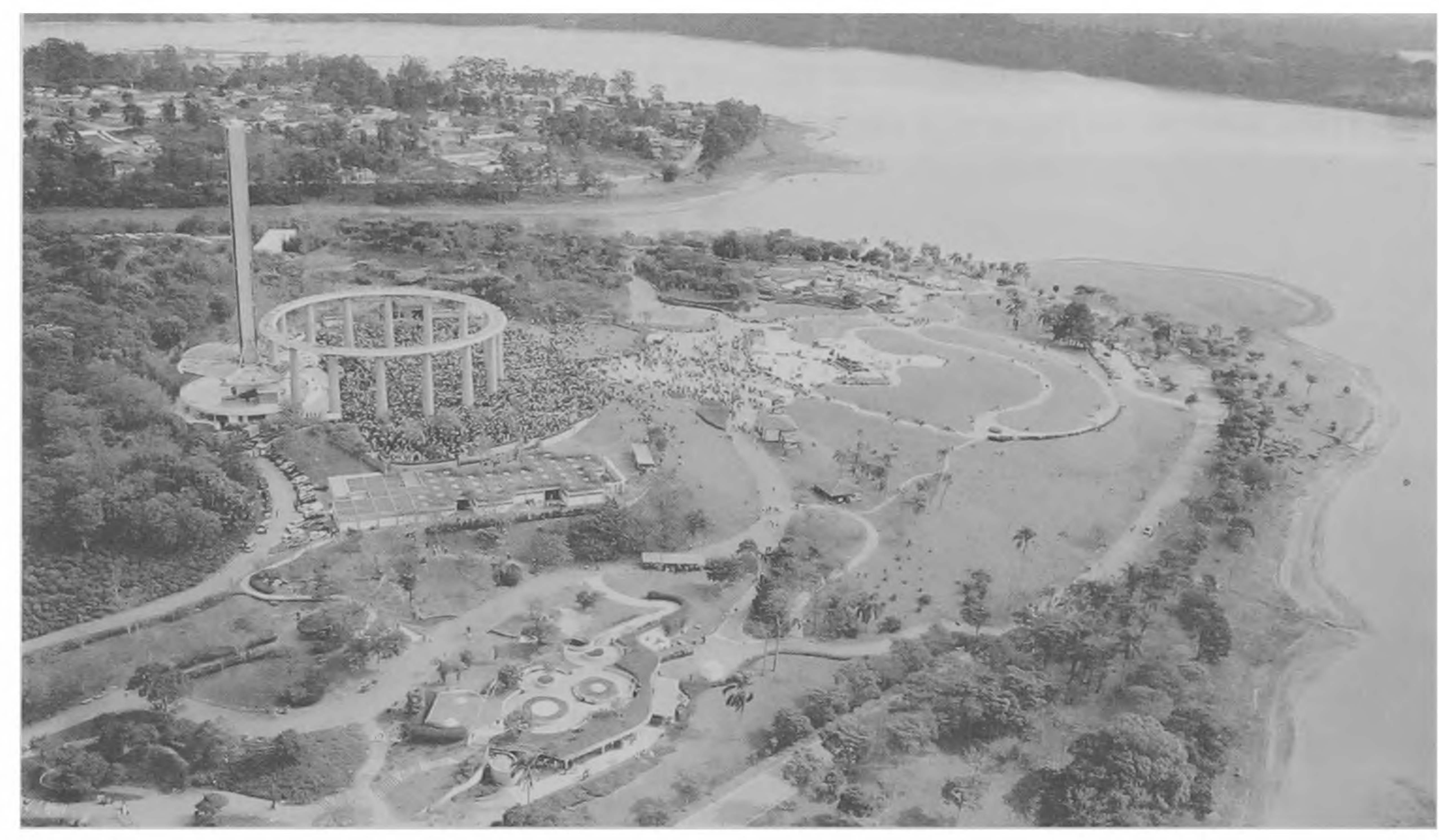

Foto1 - Solo Sagrado da Igreja Messiânica: local de paz e harmonia em meio ao caos de São Paulo.

Os cursos de Ikebana Sanguetsu e Cerâmica são ministrados, respectivamente, tanto no Espaço Cultural do Edíficio Mokiti Okada e no IACE (Instituto de Arte em Cerâmica) como em empresas, escolas e órgãos públicos. Escolas públicas fazem parcerias com a FMO e incluem os produtos do Projeto Planeta Azul em suas atividades extra-curriculares. Os produtos naturais da KORIN podem ser adquiridos em supermercados da rede Pão de Açúcar, entre outros locais.

Os professores da Academia Sanguetsu, obrigatoriamente, são adeptos da IMMB, realmente convertidos. Porém, a maior parte de seus alunos, embora pratique um estilo de Ikebana preconizado por um fundador religioso, individualmente, professa religiões diferentes da religião messiânica. Há alunos que, posteriormente, identificados com as idéias de Mokiti Okada ${ }^{11}$ até se filiam à IMMB.

Enquanto os messiânicos convertidos chamam o Fundador da IMM de "Meishu-Sama", os professores do ensino fundamental que adotam as revistas em quadrinhos do Projeto Planeta Azul em suas salas de aula, referem-se à mesma pessoa por "Mokiti Okada" Isto é, os professores e seus alunos usufruem de um produto cujo conteúdo é ético-religioso, sem necessariamente se converterem à religião messiânica.

Os aspectos morais e éticos presentes na obra escrita de Mokiti Okada norteiam o Projeto Planeta Azul; suas impressões sobre o contato com as flores e o respeito à

11. Mokiti Okada, entre outras realizações, fundou a Igreja Messiânica Mundial em 01.01.1935, no Japão. 
natureza são os princípios do Ikebana Sanguetsu e sua teoria da energia do solo, comprovada por suas experiências no cultivo livre de adubos químicos são a base da Agricultura Natural e dos projetos ambientais desenvolvidos pela FMO. É, certamente, a abrangência da doutrina messiânica que possibilita a criação de opções de consumo religioso transcendentes à religião.

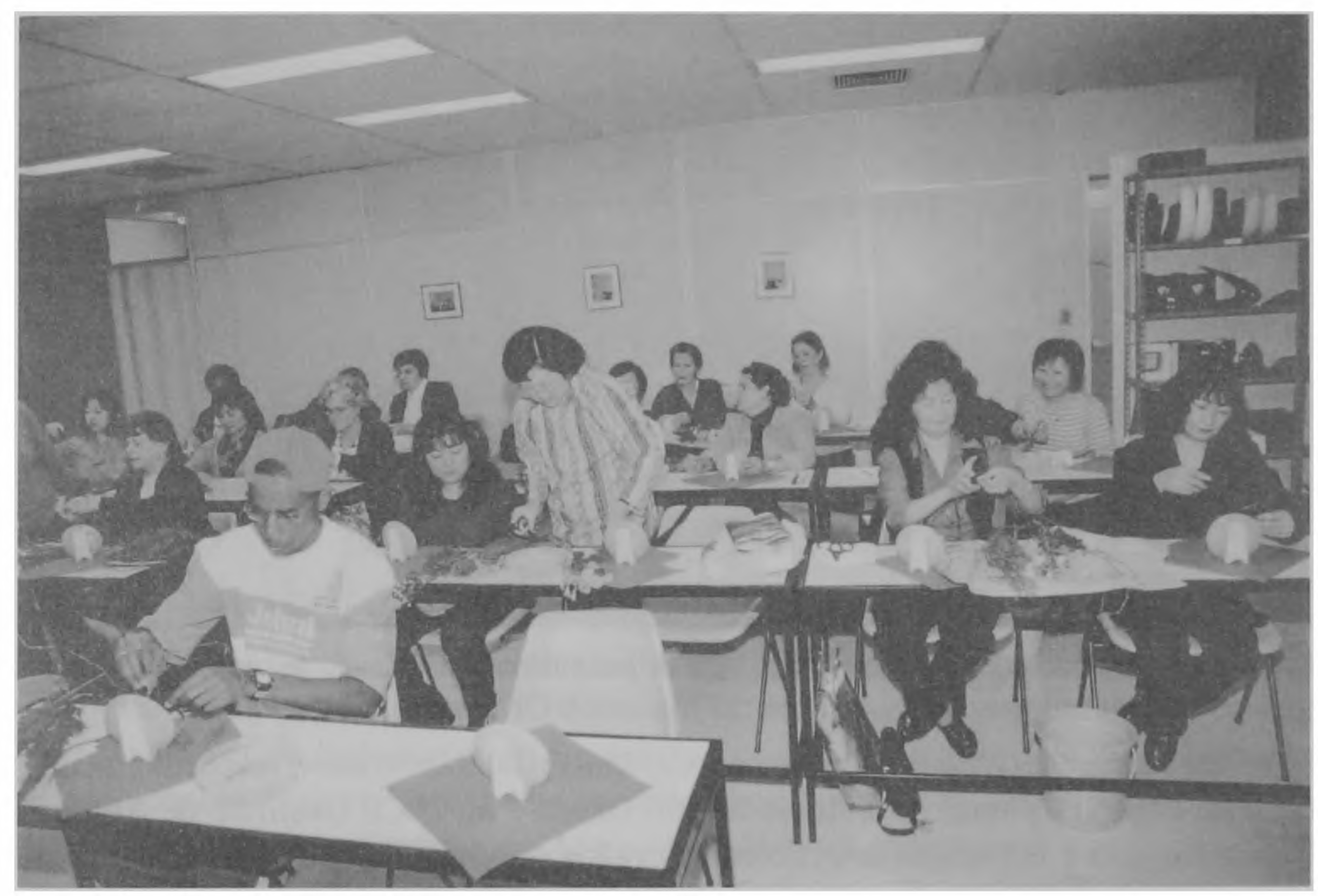

Foto 2 - Aula de Ikebana Sanguetsu: um dos projetos artístico-culturais da Igreja Messiânica.

Um dos atrativos da PL é o atendimento personalizado, que pode ser considerado um serviço. $\mathrm{O}$ adepto tem acesso, como dizem muitos, "a qualquer hora do dia ou da noite" a uma pessoa que o aconselhe e, além disso, tem competência para dizer-lhe o porquê de sua angústia e o meio de sair dela (Abreu, 1990, p. 190).

A justificativa para tal procedimento pode ser considerada a partir da própria doutrina. Os peelistas crêem no Mioshiê. "O Mioshiê significa uma orientação, inspirada por Deus, que aponta as causas espirituais dos sofrimentos dos fiéis. [...] O Mioshiê é oferecido a cada adepto individualmente. Para isso o adepto vai à sua Igreja e faz a solicitação ao Mestre, o qual em seguida encaminha a ficha de pedido de Mioshiê para a Igreja Central, em São Paulo, onde tudo é traduzido para o japonês, e posteriormente enviado ao Japão, para ser apreciado pelo Patriarca ou algum Yussô"12 (Gonçalves, 1998 p. 92).

A PL, além de suas filiais nas diversas regiões do país, possui locais diferenciados onde os fiéis podem recorrer a serviços realizados em conformidade com as orientações

12. "Yussô" significa mestre habilitado para orientar.

14 TOMITA, Andréa Gomes Santigo. Conversão e Consumo Religioso nas Novas Religiões Japonesas:... 
religiosas do Patriarca ${ }^{13}$. Entre elas, é possível destacar a Clínica de Assistência Médica PL (situada no bairro Vila Mariana-São Paulo), o Cemitério Parque Pousada da Paz e o Instituto PL de Pesquisas Botânicas, situados na Terra Sagrada da América do Sul em Arujá-SP.

Assim como os messiânicos, os peelistas também possuem um local sagrado de grandes dimensões com diversas edificações para a realização de suas atividades religiosas. Situado em Arujá, São Paulo, a Terra Sagrada abriga, entre outras edificações, um auditório com "capacidade para acomodar 1000 pessoas em poltronas confortáveis" (PL 40 anos, 1998, p. 11). (Ver Foto 3) "O Cemitério Parque Pousada da Paz, ocupado por famílias de adeptos da PL, consiste em um amplo terreno gramado para jazigos e columbários (local onde se guardam cinzas resultantes da cremação)" (Gonçalves, 1998, p. 125).

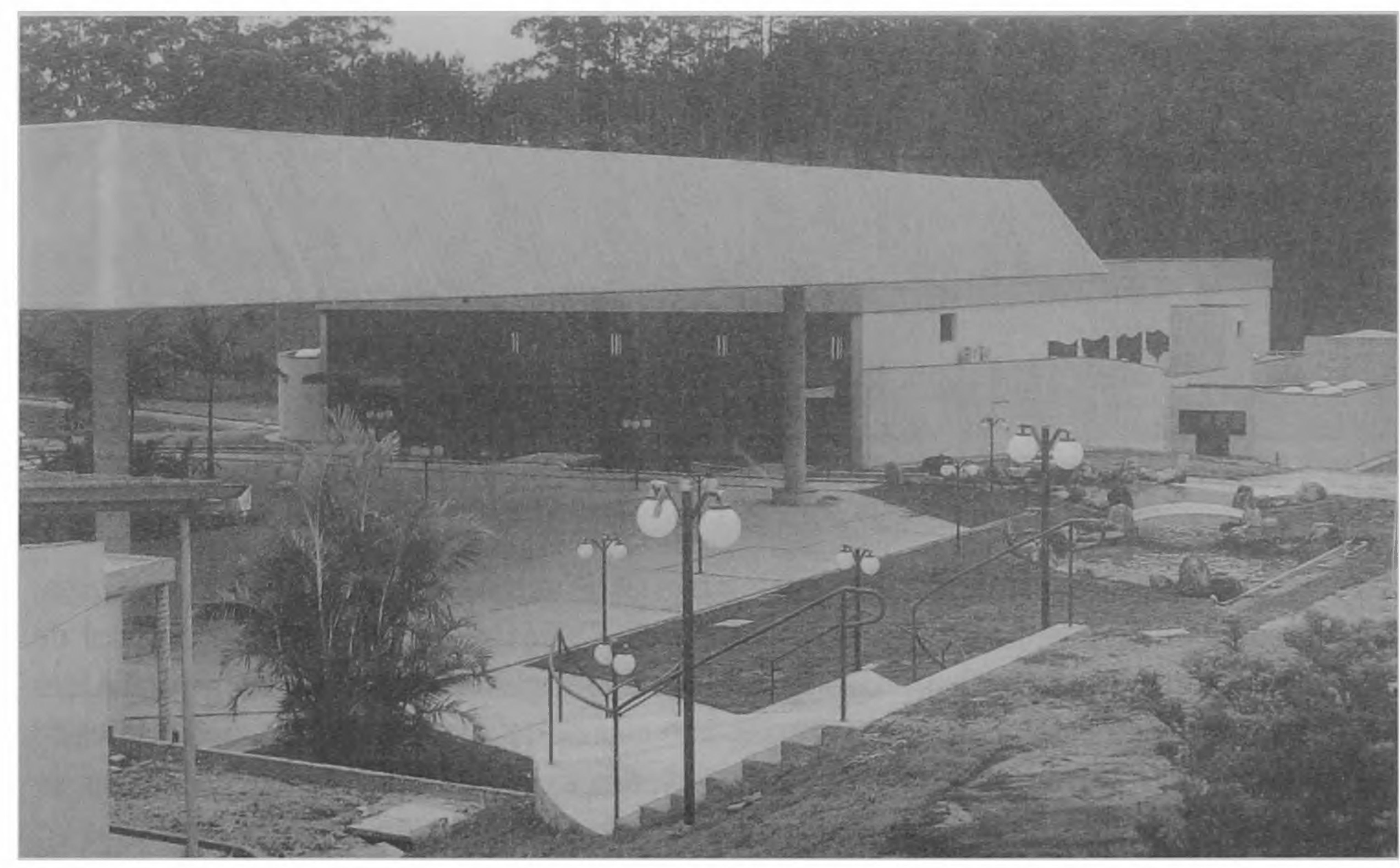

Foto 3 - Auditório situado na Terra Sagrada da PL: capacidade para 1000 pessoas.

Através da bibliografia pesquisada, pudemos observar uma constante preocupação da PL em facilitar a aproximação entre as culturas japonesa e brasileira em meio ao seu trabalho missionário. Várias foram as ações nesse sentido. O mesmo, certamente, ocorreu na IMMB ao longo dos seus 47 anos de expansão no Brasil. Entretanto, parece-nos que, comparada à IMMB, a PL oferece serviços, principalmente, aos adeptos peelistas. Por exemplo, o cemitério é destinado basicamente à comunidade peelista e a visitação

13. Na PL, o Patriarca é chamado de "Oshieoyá-Samá", isto é, Pai dos Ensinamentos. Diferentemente da IMMB, na PL, em cada época surge um fundador que orienta os peelistas o caminho da verdadeira liberdade. O atual Oshieoyá-Samá", Takahito Miki, é o III Fundador. 
à Terra Sagrada não é aberta ao público em geral, não atendendo a fins turísticos conforme acontece no Solo Sagrado da IMMB. (Ver Foto 4)

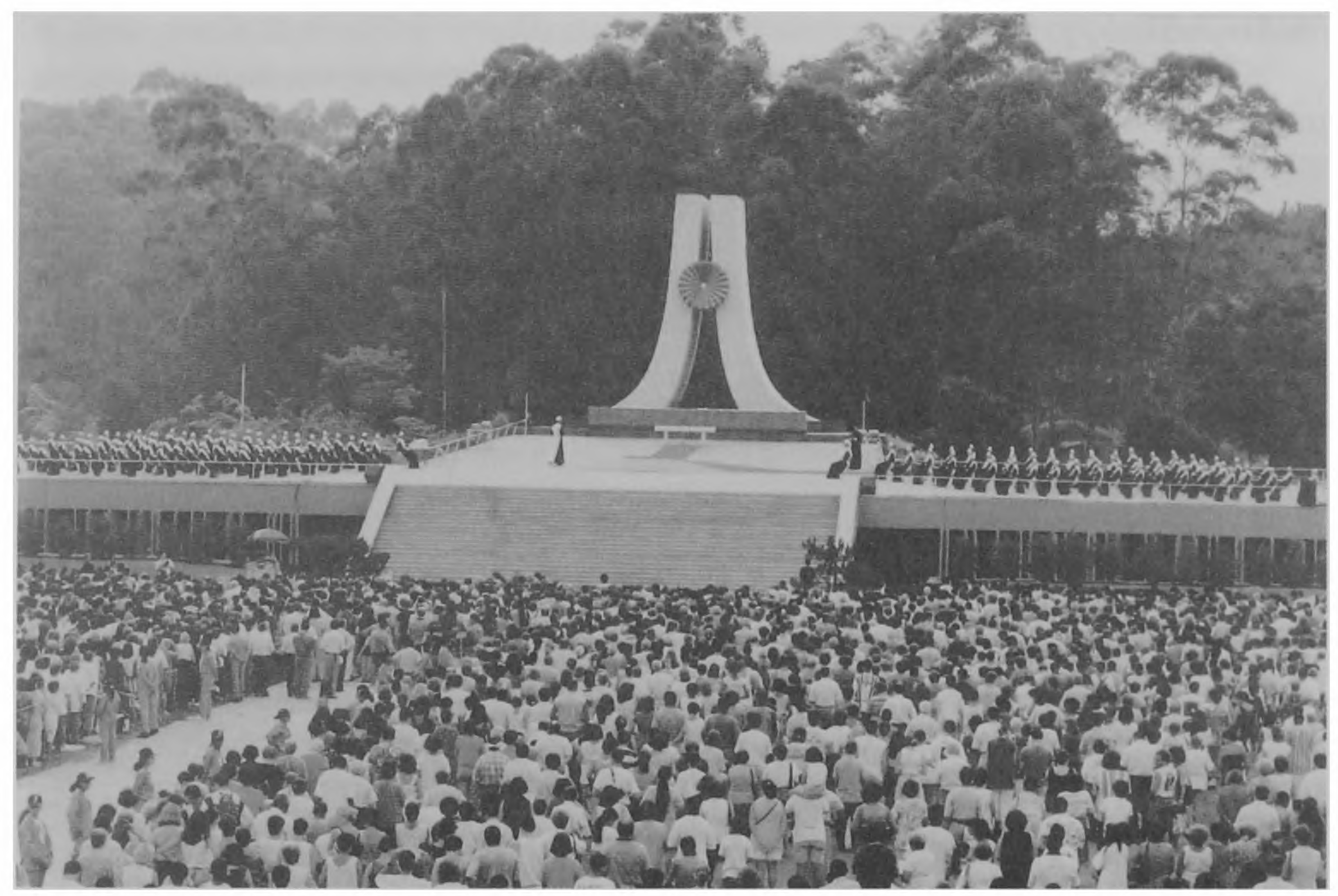

Foto 4 - Terra Sagrada da Perfect Liberty, por ocasião da cerimônia do $40^{\circ}$ aniversário da PL no Brasil.

Futuramente, seria interessante avaliar o grau de acessibilidade de conversos e nãoconversos aos diferentes serviços oferecidos pela IMMB e PL, bem como o papel de entidades coligadas na ampliação da visibilidade da religião no mercado religioso. Além disso, a questão do pagamento pelos serviços e o próprio sistema de doações praticado nas respectivas instituições, certamente, possuem aspectos distintos e relevantes se observados do ponto de vista da oferta, do mercado e do consumo religioso.

\section{Conclusão}

No passado, a conversão religiosa era um drama pessoal e familiar, entretanto, atualmente a realidade é diferente. Isto porque o converso transformou-se numa espécie de consumidor religioso. Portanto, para atender e garantir o seu mercado religioso, a religião, por sua vez, precisa mudar e adaptar-se às transformações sociais e culturais de cada época.

As NRJ, surgidas em meio à ocidentalização do Japão ou à urbanização brasileira, já nasceram e cresceram sabendo que mudanças e adaptações seriam o seu meio e fim. Certamente, foi através da adaptação em maior ou menor grau que a IMM e a PL se expandiram no Brasil. 
Independentemente da conversão, parte das NRJ apostam na diversificação de seus serviços, através de atividades extra-religiosas, como forma de se tornarem visíveis no cenário religioso brasileiro. A abrangência da doutrina permite a oferta de serviços e produtos acessíveis aos não-convertidos que, muitas vezes, partilham os mesmos princípios e "consomem a religião" sem necessariamente serem conversos.

\section{Bibliografia}

Jyoho Chishiki IMIDAS - [IMIDAS Almanaque de Informações e Conhecimentos]. Japan, Shueisha, 1999.

NAKAMAKI, Hirochika, Shukyô ni naniga Okiteiruka [O que Está Acontecendo nas Religiões?]. Tóquio, Heibonsha, 1990.

INOUE, Nobutaka (ed.). Shin Shukyô Kyodan Jinbutsu Jiten [Dicionário das Novas Religiões e Personagens]. Tokyo, Kobundo, 1996.

MATSUE, Regina Yoshie, "Overseas Japanese New Religion: The Expansion of Sekai Kyuseikyô in Brazil and Australia" Dissertação de mestrado em Area Studies, South Asia Course, apresentada à University of Tsukuba, Japan, 2002.

Clarke, Peter B. "Movimentos Milenaristas Japoneses e o Papel do Brasil na Construção do Paraíso na Terra: a Igreja Messiânica Mundial (Sekai Kyusei Kyo)". ILHA - Revista de Antropologia, vol. 2, n.1. Trad. Maria Amélia Schmidt Dickie. Florianópolis, UFSC, 2000, pp. 107-111.

FUJIKURA, Yumi. "Alguns Aspectos de Inculturação no Trabalho Missionário da PL no Brasil". Dissertação de mestrado em Ciências da Religião apresentada à Pontifícia Universidade Católica de São Paulo, 1992.

MORI, Koichi. "Vida Religiosa dos Japoneses e seus Descendentes Residentes no Brasil e Religiões de Origem Japonesa”. Uma Epopéia Moderna - 80 Anos da Imigração Japonesa no Brasil. São Paulo, Hucitec, Sociedade Brasileira de Cultura Japonesa, 1988.

GONÇALVES, Hiranclair Rosa. "Perfect Liberty: O Fascínio de uma Religião Japonesa no Brasil" Dissertação de mestrado em Ciências Sociais apresentada à Pontifícia Universidade Católica de São Paulo, 1998.

Prandi, Reginaldo. "Religião Pagã, Conversão e Serviço". In Prandi, Reginaldo \& PIERUCCI, Antonio Flavio. A Realidade Social das Religiões no Brasil. São Paulo, Hucitec, 1996.

. "Religião, Biografia e Conversão: Escolhas Religiosas e Mudanças na Religião". Tempo e Presença. São Paulo, ano 22, março-abril de 2000.

PIERUCCI, Antonio Flavio. "Liberdade de Cultos na Sociedade de Serviços". In PRANDI, Reginaldo \& PIERUCCI, Antonio Flavio. A Realidade Social das Religiões no Brasil. São Paulo, Hucitec, 1996.

Abreu, Ana Cristina de. "Diversidade Religiosa". In LANDIN, Leilah (org.). Revista Sinais dos Tempos, n. 23, ISER. Rio de Janeiro, 1990.

Alicerce do Paraíso - Ensinamentos de Meishu-Sama. São Paulo, Editora Fundação Mokiti Okada, julho 1987.

Revista Johrei - A Energia do Novo Milênio. São Paulo, Mythos Editora, dezembro 2000.

OKadA, Mokiti. A Outra Face da Doença - A Saúde Revelada por Deus. São Paulo, Editora Fundação Mokiti Okada, 1988. 
Orientação para a Vida Prática das Instruções para a Vida Religiosa PL. São Paulo, Editora Vida Artística, 2000.

PL 40 Anos - Oshieoya-Sama no Brasil. São Paulo, Editora Vida Artística, 1998.

TOMITA, Andréa Gomes Santiago. "Elaboração de Glossário de Termos Relacionados a uma Nova Religião Japonesa" (Monografia de conclusão do curso "Lexicografia e Terminologia em Língua Portuguesa”) (USP/FLC5722), 2001. 